\title{
Los problemas de la gestión patrimonial en espacios traumáticos. La actuación sobre la memoria de la Guerra Civil en la provincia de Jaén
}

Francisco Delgado Chica | Historiador del arte

URL de la contribución <www.iaph.es/revistaph/index.php/revistaph/article/view/5037>

La musealización de espacios traumáticos como el campo de concentración de Crveni Krst en Niš (Serbia) o Auschwitz-Birkenau en Polonia es frecuente en Europa. Muy conocido es el segundo, inscrito en la Lista de Patrimonio Mundial en 1979 (Unesco 2021), así como los problemas que conlleva su turismo masificado. La llegada numerosa de visitantes a estos lugares ha causado problemas como la mercantilización del holocausto (Rojas 2019) o los selfies (EFE 2019). Algo similar ocurre con el interés turístico que suscita la ciudad fantasmal de Pripyat tras la explosión de 1986, ya que muchos turistas "acuden a Chernóbil como quien va a ver una atracción de feria" (Marquina Montañana 2019), turismo acrecentado más aún tras el estreno de la serie de HBO Chernóbil el 6 de mayo de 2019. Bajo mi opinión, el interés que suscitan estos lugares a la mayoría de visitantes (sin incluir a aquellos colectivos afectados en el mismo) se debe a su apreciación 'sublime' en términos de Edmund Burke: "con cierta distancia" y con la seguridad de que forman parte del pasado (Burke 2014, 137). Son espacios conflictivos donde se han producido matanzas, genocidios, masacres, etc. (Maraña Montañana 2021, 44) y entran en juego cuestiones éticas, políticas o económicas al actuar sobre nuestra memoria más reciente y traumática con objeto de no repetir los errores cometidos y de homenajear a las víctimas.

Es por ello que España buscó recuperar la memoria histórica de la Guerra Civil española (1936-1939) y aprobó la Ley 52/2007, así como en Andalucía entró en vigor la Ley 2/2017 de Memoria Histórica y Democrática de Andalucía donde se afirma que "recuperar dicha memoria es la forma más firme de asentar nuestro futuro de

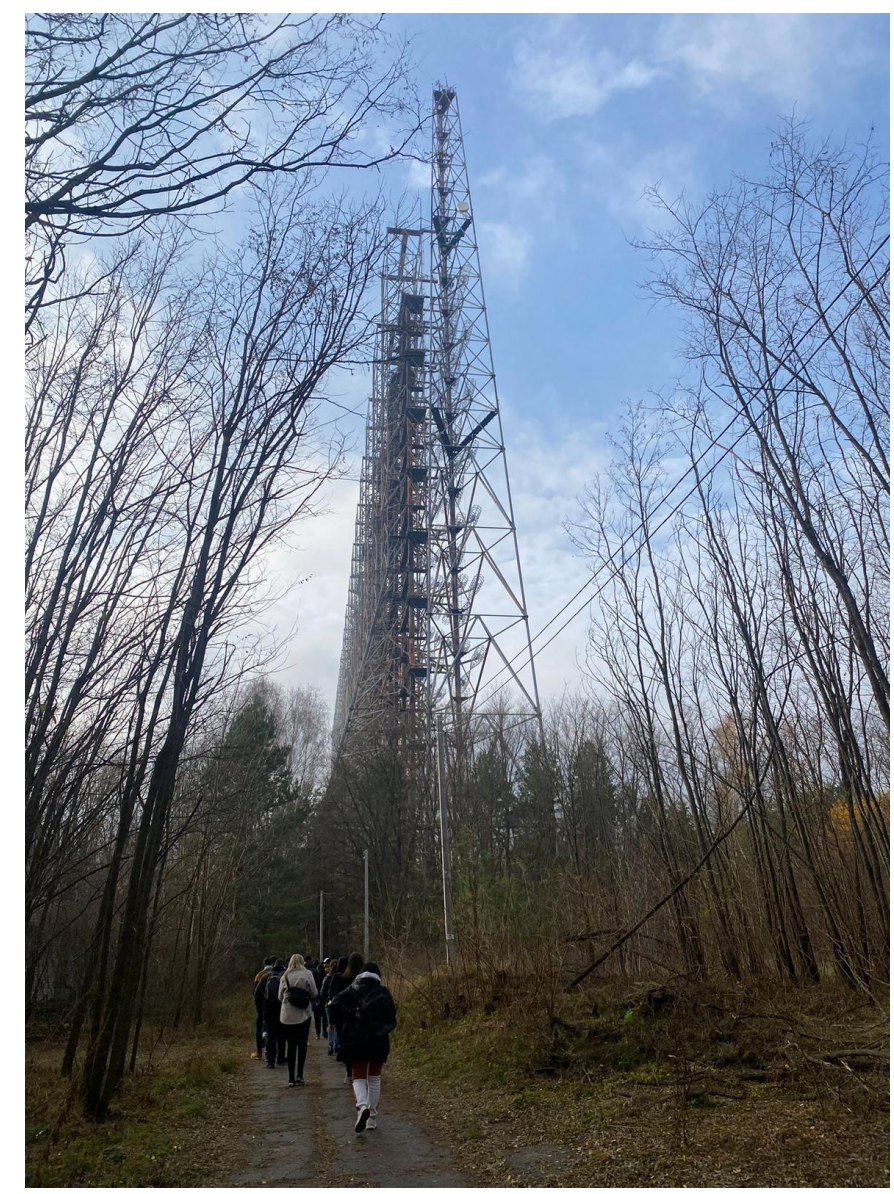

Visita turística a Chernóbil, noviembre de 2021 | foto Francisco Delgado Chica

convivencia y paz" (Ley 2/2017, 5). En este sentido, ya se había puesto en marcha un reconocimiento de espacios traumáticos mediante el Decreto 264/2011, creando la figura de Lugar de Memoria Histórica de Andalucía y el Catálogo de Lugares de Memoria Histórica de Andalucía, 
a debate Interpretación y gestión del patrimonio en los espacios del turismo oscuro

| coordinan Óscar Navajas Corral y Maribel Rodríguez Achútegui

con la inclusión de fosas comunes como la de Martos en la provincia de Jaén (Consejería de Cultura y Patrimonio Histórico 2021). El inventario de estos lugares es un paso más hacia la salvaguardia de la memoria de la resistencia del pueblo andaluz; sin embargo, la tutela patrimonial de los mismos puede crear conflictos ya que, aunque hablemos de lugares de memoria histórica, memoria e historia no siempre coinciden. Pese a que en ocasiones se usan como sinónimos -y, así como la memoria bebe de la historia, la historia bebe de la memoria (Lowenthal 1998, 310)-, la historiografía las ha considerado a veces como opuestas, de modo que, frente a la objetividad que nos ofrece la historia, "la memoria es insegura, frágil e inestable" (Ballart 1997, 30), lo cual no nos permite aplicar los principios de objetividad, rigor o distancia del patrimonio histórico (Castillo Ruiz 2021, 9).

Pese a que muchos bienes forman parte de nuestra memoria, el art. 32.3. de la Ley de Memoria Histórica y Democrática de Andalucía ${ }^{1}$ pondría en tela de juicio la vidriera en honor a Franco de la Catedral de Baeza ${ }^{2}$ o la protección patrimonial del conjunto escultórico del Santuario de la Virgen de la Cabeza en Andújar, el cual rinde homenaje al capitán Cortés y a los sublevados del bando franquista ${ }^{3}$ (Jaén Milla 2012, 50). Sin embargo, si nos ceñimos al art. 4 de dicha ley, sería muy sugerente poner en valor otros "vestigios" de la Guerra Civil en la provincia de Jaén ${ }^{4}$ como casamatas, fortines antitanques, nidos de ametralladoras o reductos, promover el conocimiento de campos de concentración como los de Higuera de Calatrava y Santiago de Calatrava que poca gente $\operatorname{conoce}^{5}$ (Jaén Milla 2012, 55) y refugios antiaéreos como el de la Plaza de la Encarnación de Arjonilla o el de la Plaza de Santiago de Jaén -ya musealizados desde el verano de 2009- (Jaén Milla 2012, 126).

Torredonjimeno se situó al frente de la línea de guerra debido a la resistencia por parte del bando republicano frente a los sublevados, desencadenando una serie de conflictos como bombardeos en los que la aviación rebelde "acabó con la vida de 21 personas en Linares y Torredonjimeno" (Jaén Milla 2021, 83). Además, su ubicación la convirtió en un punto clave frente a Porcuna,

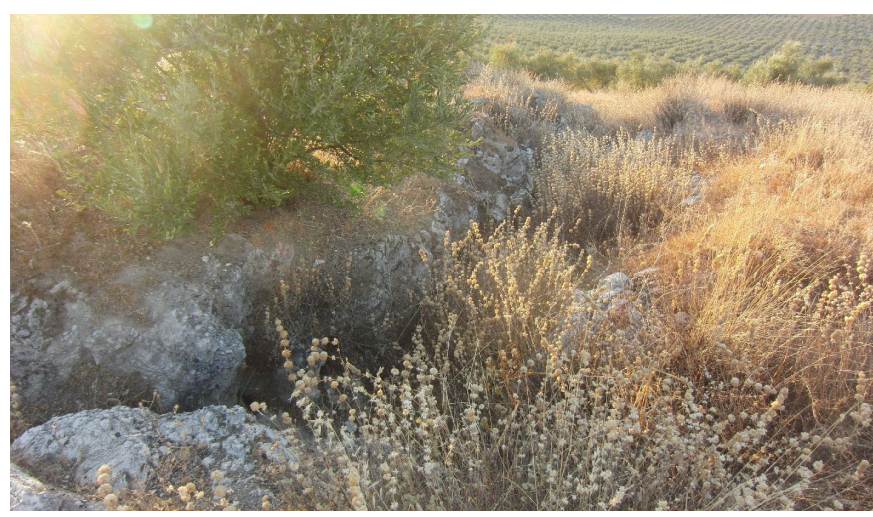

Trinchera de Piedras Cucas | foto Francisco Miguel Merino Laguna, 2017 (Jaén escondido)

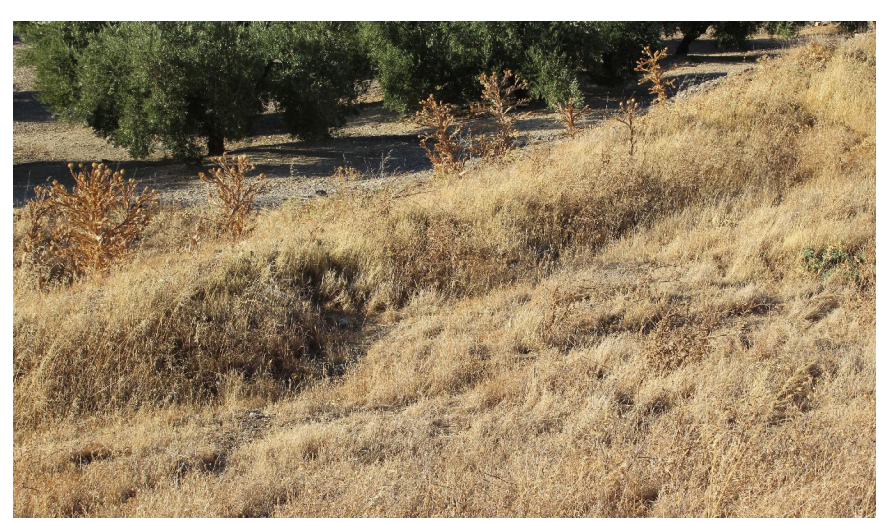

Trinchera de Torre Alcázar | foto Francisco Miguel Merino Laguna, 2017 (Jaén escondido)

ocupada por los sublevados a lo largo de 1937, o Alcalá la Real, ocupada desde el 30 de septiembre de 1936 (Jaén Milla 2012, 114). Este fue el móvil para que el bando republicano ejecutase un programa defensivo frente al bando sublevado (Jaén Milla 2012, 22) y que hoy se puede reconocer en dos trincheras conservadas.

La trinchera de Piedras Cucas se encuentra cerca de Aldea Lendínez y se caracteriza porque permitió a los republicanos controlar los movimientos de Porcuna, Lopera, Santiago o Higuera y estar conectados con Martos y Torredonjimeno (Merino, 2021). La buena conservación de la trinchera se debe, según Santiago Jaén Milla, "al encontrarse en una loma y no haber sido explotada desde el punto de vista agrícola" $(2012,112)$, per- 
mitiendo ver aún las galerías excavadas en la tierra y las líneas en zigzag de la fortificación. Para su puesta en valor, será apropiada la inclusión en inventarios patrimoniales con su respectiva conservación, la colocación de paneles informativos que cuenten los acontecimientos ocurridos o la difusión desde la localidad de Torredonjimeno para un mayor conocimiento de su memoria con exposiciones o señalética, creando un itinerario que vaya desde el núcleo urbano hasta la misma trinchera.

La trinchera en la Cortijada de Torre Alcázar se corresponde con tres niveles de zanjas excavadas en la tierra y se sitúa de nuevo en una loma sin explotar y a 6 kilómetros de Carrajaén, nido de ametralladoras, en la localidad de Porcuna (Jaén Milla 2012, 118), por lo que, gracias a ella, los sublevados de esta localidad se mantuvieron inmóviles durante dos años. Se ubica en las inmediaciones de Torre Alcázar, tutelado de manera genérica por el Decreto del 29 de abril de 1949 sobre la protección de los castillos españoles, y declarado bien de interés cultural con la Ley 16/1985, de 25 de junio, de Patrimonio Histórico Español según la disposición adicional primera. Una de las novedades que sugiere el anteproyecto de modificación de esta ley publicado en junio de 2021 es la de individualizar estos bienes que habían sido protegidos de manera genérica6, por lo que sería muy interesante incluir en el análisis histórico-artístico del futuro informe de la torre la relevancia del entorno durante el conflicto en la provincia, además de llevar a cabo las actuaciones de tutela comentadas para la trinchera anterior (conservación, señalética, exposiciones, itinerarios, etc.).

Como conclusión, asumimos que existe un gran interés por visitar espacios conflictivos o traumáticos como los relacionados con la Guerra Civil española y la gestión patrimonial debe actuar sobre estos y adecuarse al marco normativo de la memoria histórica. Esto nos conduce a detectar bienes heredados de la guerra que, por cuestiones éticas, son puestos en tela de juicio, y bienes que, debido a sus valores, deberían preservarse como los incluidos en el Catálogo de Lugares de Memoria Histórica de Andalucía e inventarios como el de la pro- vincia de Jaén. Por ello, la tutela de las trincheras de Torredonjimeno será una actuación idónea para recuperar la memoria de la localidad y salvaguardar su herencia.

\section{NOTAS}

1. "Artículo 32.3. No se considerará que concurren razones artísticas o arquitectónicas para el mantenimiento de los elementos de exaltación de la Dictadura, salvo informe favorable técnico jurídico en tal sentido de la Consejería competente en materia de patrimonio histórico, que se emitirá por esta en el plazo de tres meses a solicitud de la persona interesada en los siguientes supuestos: Placas, escudos, insignias, inscripciones sobre edificios o lugares históricos; Alusiones que desmerezcan a la legalidad republicana o sus defensores; Alusiones a los participantes, instigadores y/o legitimadores de la sublevación militar de 1936 y de la Dictadura franquista."

2. Pese a ser ejecutado el escudo por la Unión de Artistas de Vidrieras de Irún, no consta de ningún informe que justifique su valor artístico (Merino 2014).

3. El Santuario fue reconstruido tras la guerra pero se conservó un lateral del inmueble donde la tradición dice que cayó mortalmente herido el capitán Cortés.

\section{4. "Artículo 4. Se entiende por a) Memoria Democrática} de Andalucía: la salvaguardia, conocimiento y difusión de la historia de la lucha del pueblo andaluz por sus derechos y libertades..."

5. "Me ha ocurrido que, al hablar de estos campos de concentración en clase, algún alumno comentaba extrañado que nunca había escuchado hablar de ellos" (Luz 2019).

6. Anteproyecto de Ley por la que se modifica la Ley 16/1985, de 25 de junio, del Patrimonio Histórico Español, y la Ley 10/25, de 26 de mayo, para la salvaguardia del Patrimonio Cultural Inmaterial: "Además, se recoge la necesidad de que los castillos, torreones, murallas y 
demás elementos de arquitectura defensiva sean declarados específica e individualizadamente pese a la protección genérica otorgada por la ley..." (Ministerio de Cultura y Deporte 2021, 10).

\section{BIBLIOGRAFÍA}

- Ballart, J. (1997) El patrimonio histórico y arqueológico: valor y uso. Barcelona: Editorial Ariel S.A.

- Burke, E. (2014) Una investigación filosófica sobre el origen de nuestras ideas de lo sublime y lo bello. 1. ${ }^{\mathrm{a}}$ ed. 1757. trad. Gras Balaguer, M. y López Férez, J.A. Madrid: Alianza Editorial

- Castillo Ruiz, J. (2021) El patrimonio cultural podría estar en peligro y los responsables son la memoria, la salvaguardia, la comunidad y el paisaje cultural (además del turismo, claro). erph_revista electrónica de patrimonio histórico, $\mathrm{n} .{ }^{\circ}$ 28, pp. 3-38. Disponible en: https://dx.doi.org/10.30827/erph. vi28.21530 [Consulta: 14/07/2021]

- Consejería de Cultura y Patrimonio Histórico, Junta de Andalucía (2021) Carretera de Víznar a Alfacar (Granada). Lugares de Memoria Histórica y Democrática de Andalucía. Disponible en: https://www.juntadeandalucia.es/organismos/ culturaypatrimoniohistorico/areas/memoria-democratica/ lugares-memoria-democratica/paginas/carretera-viznaralfacar.html [Consulta: 30/10/2021]

- Decreto 264/2011, de 2 de agosto, por el que se crean y regular la figura de Lugar de Memoria Histórica de Andalucía y el Catálogo de Lugares de Memoria Histórica de Andalucía. Boletín Oficial de la Junta de Andalucía, n. ${ }^{0}$ 158, de 12 de agosto de 2011. Disponible en: https://www.juntadeandalucia. es/boja/2011/158/3 [Consulta: 30/10/2021]

- EFE (2019) Auschwitz pide evitar los 'selfies' durante la visita al campo de concentración. El País, 23 de marzo de 2019. Disponible en: https://elpais.com/cultura/2019/03/22/ actualidad/1553271474_129297.html [Consulta: 30/10/2021]

- Jaén Milla, S. (2012) Un patrimonio por descubrir: vestigios arquitectónicos de la guerra civil en la provincia de Jaén. Jaén: Universidad

- Ley 16/1985, de 25 de junio, del Patrimonio Histórico Español. Boletín Oficial del Estado, n. ${ }^{\circ}$ 155, de 29 de junio de 1985. Disponible en: https://www.boe.es/buscar/act. php?id=BOE-A-1985-12534 [Consulta: 30/10/2021]

- Ley 52/2007, de 26 de diciembre, por la que se reconocen y amplían derechos y se establecen medidas en favor de quienes padecieron persecución o violencia durante la guerra civil y la dictadura. Boletín Oficial del Estado, n. ${ }^{\circ} 310$, de 27 de diciembre de 2007. Disponible en: https://www.boe.es/buscar/ act.php?id=BOE-A-2007-22296 [Consulta: 29/10/2021]

- Ley 2/2017, de 28 de marzo, de Memoria Histórica y Democrática de Andalucía. Boletín Oficial de la Junta de Andalucía, n. ${ }^{\circ} 63$, de 3 de abril de 2017. Disponible en: https:// www.boe.es/buscar/pdf/2017/BOE-A-2017-4348-consolidado. pdf [Consulta: 29/10/2021]

- Lowenthal, D. (1998) El pasado es un país extraño. Madrid: Ediciones AKAL, S.A.

- "Luz" para dos desconocidos campos de concentración (2019) Diario de Jaén, 17 de enero de 2019. Disponible en: https:// www.diariojaen.es/provincia/luz-para-dos-desconocidoscampos-de-concentracion-GB5074594 [Consulta: 12/11/2021]

- Maraña, M. (2021) Sitios vinculados a conflictos como categoría patrimonial. Análisis desde el debate actual en UNESCO. erph revista electrónica de patrimonio histórico, n. ${ }^{\circ} 28$, pp. 39-65. Disponible en: https://dx.doi.org/10.30827/ erph.vi28.21410 [Consulta: 14/07/2021]

- Marquina Montañana, R. (2019) Cómo es y cuánto cuesta visitar Pripyat, la ciudad fantasmal más cercana a Chernobyl. Infobae, 25 de junio de 2019. Disponible en: https://www. infobae.com/america/mundo/2019/06/25/como-es-y-cuantocuesta-visitar-pripyat-la-ciudad-fantasmal-mas-cercana-achernobyl/ [Consulta: 30/10/2021]

- Merino Laguna, F.M. (2021) Trincheras de Piedras de Cuca. Francis. Disponible en: http://www.redjaen.es/ francis $/ ? \mathrm{~m}=\mathrm{c} \& \mathrm{o}=157411$ \&letra $=\& o r d=\& i d=200242$ [Consulta: $31 / 10 / 2021]$

- Merino, A. (2014) Baeza (Jaén). La catedral alberga vidrieras en honor de Franco. Todos los nombres. 31 de diciembre de 2014. Disponible en: https://todoslosnombres.org/content/ noticias/baeza-jaen-la-catedral-alberga-vidrieras-en-honorfranco [Consulta: 10/08/2021]

- Ministerio de Cultura y Deporte (2021) Anteproyecto de Ley por la que se modifican la Ley 16/1985, de 25 de junio, del Patrimonio Histórico Español, y la Ley 10/2015, de 26 de mayo, para la salvaguardia del Patrimonio Cultural Inmaterial. Ministerio de Cultura y Deporte, de junio de 2021. Disponible en: https://www.culturaydeporte.gob.es/en/dam/jcr:77f6deb646c2-4522-9d4b-227faa35c8eb/apl-modifican-Iphe-pci.pdf

- Rojas, A. (2019) El Auschwitz Memorial critica a una web que vende ropa con imágenes del Holocausto. El Mundo, 7 de mayo de 2019. Disponible en: https://www.elmundo.es/ internacional/2019/05/07/5cd1d0f221efa0ef708b456e.html [Consulta: 30/10/2021]

- Unesco [United Nations Educational, Scientific and Cultural Organization] (2021) Auschwitz Birkenau Campo nazi alemán de concentración y exterminio (1940-1945). Lista de Patrimonio Mundial. Disponible en: https://whc.unesco.org/es/list/31 [Consulta: 30/10/2021] 